\title{
Long-lived marine species may be resilient to environmental variability through a temporal portfolio effect
}

\author{
Jacek Maselko ${ }^{1}$, Kimberly Andrews ${ }^{2}$, and Paul Hohenlohe ${ }^{2}$ \\ ${ }^{1} \mathrm{NOAA}$ \\ ${ }^{2}$ University of Idaho
}

May 5, 2020

\begin{abstract}
Maintenance of a portfolio of adaptive alleles may provide resilience of populations to natural environmental variability. We used Pacific ocean perch (POP; Sebastes alutus) to test for the maintenance of adaptive variation across overlapping generations. POP are a long-lived species characterized by widespread larval dispersal in their first year and a longevity of over 100 years. In order to understand how early marine dispersal affects POP survival and population structure, we used Restriction Site Associated DNA sequencing (RADseq) to obtain 11,146 single-nucleotide polymorphisms (SNPs) from 401 young-of-the-year (YOY) POP collected during surveys conducted in 2014 (19 stations) and 2015 (4 stations) in the eastern Gulf of Alaska. Population clustering analysis showed that the POP samples represented four distinct ancestral populations mixed throughout the sampling area. Based on prior work on larval dispersal of POP, these larvae are most likely from distinct parturition locations that are mixing during their pelagic dispersal life stage. Latent factor mixed models revealed that POP larvae face significant selection during their first year at sea, which were specific to the year of their birth. Thus each adult cohort's genetic composition is heavily influenced by the environmental conditions experienced during their first year at sea. Long-lived species relying on broadcast spawning strategies may therefore be uniquely resilient to environmental variability by maintaining a portfolio of cohort-specific adaptive genotypes, and age truncation due to overfishing of older cohorts may have detrimental effect on the population viability.
\end{abstract}

\section{KEYWORDS}

Selection, genotype-environment association, adaptive variation, portfolio effect, selective sieve, RADseq

\section{1 | INTRODUCTION}

Understanding the resilience of biological marine resources to changing oceanographic conditions is central to ecosystem-based fisheries management and the implementation of adaptive sustainable harvest strategies (Link 2002; Levin and Möllmann 2015). The ability of populations to respond to disturbances in their habitat is in part determined by the genetic diversity present in the population (Parker et al. 2000; Hoffman and Sgro 2011). This genetic diversity, exhibited by a portfolio of available gene variants, allows for a quick response if selectively advantageous variants are already present in the population (Sunday et al. 2011; Pacifici et al. 2017). Understanding the response of marine populations to environmental perturbations will allow us to readily assess the resilience or vulnerability of these populations and species.

Measuring differential survival between subpopulations reveals how environmental conditions can influence the overall productivity of exploited populations. For example, Schindler et al. (2010) demonstrated that environmental conditions favored the production of discrete salmon populations residing in Bristol Bay, Alaska. Maintenance of a portfolio of locally adapted genotypes ensured adult returns to the region, but returns to different streams were maximized under different environmental conditions. This maintenance 
of a portfolio of adaptive alleles may be a key aspect of resilience of populations to natural environmental variability.

The idea of a temporal portfolio effect, in which adaptive variation is maintained by overlapping generations in a temporally variable environment, has been studied in general (Ellner and Hairston 1994). For example, many freshwater zooplankton taxa have relatively short-lived adults that may be subject to strong selection, but eggs can remain viable for decades in sediment, resulting in persistent egg banks that are relatively buffered from environmental variation (Brendonck and DeMeester 2003). We hypothesize that a similar effect may occur in marine fish species with highly dispersive larvae and long-lived, relatively sedentary adults. The genetic composition of each recruitment cohort may reflect relatively strong selection during the larval stage, while the adult population would maintain genetic variation reflecting multiple cohorts. Here we test this hypothesis using genomic methods for detecting population structure and adaptive loci.

Genomic data allow us to scan for individual and population-level differences across the whole genome, and genomics is becoming integral in answering a wide array of previously unresolved questions in conservation biology with numerous applications in fisheries (Wenne et al., 2007; Barrio et al. 2016; Jasonowicz et al., 2016; Valenzuela-Quiñonez, 2016; Kumar and Kocour, 2017). It is now possible to estimate, with a high level of precision and certainty, the demographic structure of fish populations at small spatio-temporal scales, and to identify local adaptation from genomic data (Wang and Höök, 2009; Barrio et al., 2016; Catchen et al. 2017; McKinney et al. 2017). RADseq approaches have been extensively used to describe various biological and ecological phenomena, such as phylogeography, population differentiation and structure, population and individual admixture (composition of lineages), genetic diversity, and outlier loci detection, among others (Alexander et al. 2009; Andrews et al. 2016; Narum et al. 2013).

Our model species, the Pacific ocean perch (POP; Sebastes alutus), is a long-lived species with its oldest individuals being over 100 years old (Conrath and Knoth 2013). POP are the most abundant and economically important rockfish species in the Gulf of Alaska (Conrath and Knoth 2013) with landings in excess of 55,000 tons in 2017 (NOAA 2019). The fishery is managed using an age-structured model where the vital population rates are derived from the abundances of different ages in the catch (Megrey 1988; Hulson et al. 2017), but the relationship between the abundance of spawning fish and their offspring cohort is highly variable and unpredictable. This extreme annual fluctuation in success and failures of various year classes has been noted as a characteristic of this and many other commercially exploited species (Westrheim 1958; Carlson and Haight 1976).

POP in the Gulf of Alaska live on the upper slope of the continental shelf. They spawn from September through November, with parturition occurring in April through May the following year, when larvae rise from demersal spawning habitats on the continental shelf break $(150-400 \mathrm{~m}$ depth) to surface waters. They then become part of the ichthyoplankton and within a few weeks metamorphose to a young-of-the-year form (YOY). They are carried in the surface waters by currents and settle out of the water column in nearshore rocky habitat by the end of their first year (Carlson and Haight 1976; Major and Shippen 1970). During their shoreward movement, larvae grow rapidly and allocate significant amounts of energy to creating lipid tissue. This lipid tissue is apparently lost during settlement (Moss et al. 2016), suggesting energy acquisition and growth are important determinants of settlement success (Hoey and McCormick 2004). They remain in the nearshore habitat for the next few years until they join the discrete adult schools residing on the continental shelf and slope (Love et al. 2002). They reach sexual maturity at eight to ten years of age and repeatedly spawn until their hundredth year or longer (Hulson et al. 2017). These adult schools are genetically differentiated and the degree of their differentiation $\left(F_{S T}\right)$ is correlated to the geographic distance between them (Palof et al. 2011).

Larval dispersal pathways in POP may be highly variable from year-to-year since they mostly depend on ocean currents in a given year (Mundy et al. 2010). An important prediction of ocean current and dispersal models (Stockhausen 2009; Stockhausen and Hermann 2007) is that in each year, the larvae at a given pelagic location are comprised of mixtures of individuals from different spawning locations indicating a high degree of mixing among them. However, population genetic studies of young-of-the-year and adults indicate there 
is limited mixing among subpopulations (Palof et al., 2011; Kamin et al., 2014). The Kamin et al. (2014) follow up study examined the YOY POP catches corresponding to locations near the adults caught by Palof et al. (2011). Their work showed that the collections of YOY POP were most related to the linearly closest adult populations. Either widely dispersed juveniles are able to return to their natal areas, or survival is maximized among locally retained larva, possibly due to local adaptation.

Here, we test whether POP larvae exhibit signatures of selection that could allow for the maintenance of a portfolio of adaptive variation in the multi-cohort adult population. We examined YOY POP collected from the eastern Gulf of Alaska during two years (2014 and 2015), when the oceanographic conditions were drastically different, with 2014 being an average temperature year, and 2015 being anomalously warm which is expected to have a negative impact on the fish (Cavole et al. 2016; Gentemann et al. 2017; Jones et al. 2018). We evaluated the potential for differences in selection strength for YOY POP across years by testing whether the fish differed in physiological conditions in 2014 and 2015, measured as a body condition index based on weight-length relationships, and total lipid content. We then used genotype environment association (GEA) tests with RADseq genomic data to test for differences in selection acting on the genome to favor different phenotypes between the two years. Finally, we identified candidate biological pathways on which selection was acting in the two different YOY cohorts. We predicted that the strength of selection would be higher in 2015 than 2014 due to the unusually high 2015 sea temperatures, resulting in poor body condition and a greater number of SNPs associated with environmental variables and physiological condition in the 2015 dataset. These findings may explain the difference in recruitment for the 2014 and 2015 cohorts as estimated in the 2017 stock assessment (Hulson et al., 2017).

\section{2 | MATERIALS AND METHODS}

\section{1 | Sample collection and processing}

Young-of-the-year (YOY) POP were collected during NOAA oceanographic surveys in the summer of 2014 and 2015 (Figure 1). POP larvae and YOY were distinguished from congenerics (Kendall et al., 2007) using diagnostic SNPs (Garvin et al., 2011) prior to inclusion in this study. The resulting sample size of identified YOY POP was 399 fish in 2014 and 108 in 2015.

Fish length, weight, and lipid content for each identified POP fish were measured at Auke Bay Laboratories in Juneau, AK. Lipid content was extracted using the Folch method (Folch et al. 1957) and quantified using the colorimetric sulpho-phospho-vanillin (SPV) method (Chabrol and Charonnet, 1937). Condition index was calculated as the residual value from a $\log$ (weight) $\sim \log ($ length) linear regression. This index accounts for the different lengths due to age of the YOY fish where a positive residual indicates better body condition than expected (Froese, 2006). Finally, for DNA analysis, a small tissue plug was extracted through an incision in the abdominal wall that included the heart tissue and stored in $95 \%$ ethanol.

\section{2 | Molecular analysis}

DNA was extracted from the muscle plug from the 515 individual fish into 96-well plates with the QIAGEN DNeasy Blood and Tissue Kits as described by the manufacturer (QIAGEN, Inc.). In brief, small pieces of tissue ( $20 \mathrm{mg}$ ) were excised from each muscle plug. The tissue pieces were digested in a proteinase solution for at least 3 hours at $55^{\circ} \mathrm{C}$. Protease digestions were performed in 96 well plates. After digestion, the samples were purified with either QIAxtractor or Corbett X-tractor robot producing eluted DNA which was stored at $-20{ }^{\circ} \mathrm{C}$.

RADseq library preparation was done for all 515 samples plus eight samples that were replicates according to Ali et al. (2016) and refined by Andrews et al. (2018) using the Sbf1 restriction enzyme, which cuts at an eight-base recognition site. Custom eight-base biotinylated barcodes were ligated to the cut site allowing multiplexing of groups of 96 samples. The multiplexed samples were then sheared to $400 \mathrm{bp}$ using Covaris M220 sonicator. This was followed by a Streptavidin bead assay to exclude sheared fragments that did not include the biotinylated barcodes. Illumina's NEBNext ultra DNA library prep kit was then used to add Illumina adapters with indexes unique to each of the multiplexed groups of 96 samples to allow further 
pooling and Illumina sequencing compatibility. 150 bp paired end sequencing was done on two lanes at the Berkeley Genomics Center Laboratory (https://qb3.berkeley.edu/gsl/) using Illumina HiSeq 4000.

\subsection{Sequencing and data processing}

We followed the bioinformatic pipeline described in Andrews at al. (2018; Figure 1), with slight modification for STACKS version 2.0 (Catchen et al. 2013). Briefly, a custom PERL script was used to flip the raw reads so that each 140 bp read was aligned starting with the barcode, and the Sbf1 cutsite sequence. STACKS 2.0 (Catchen et al. 2013) program process_radtags was used to demultiplex the raw reads followed by program clone_filter to remove PCR duplicates. BOWTIE2 version 2.3.4.3 (Langmead and Salzberg; 2012) was used to align the sequences to Sebastes nigrocinctus reference genomes downloaded from the ncbi database (https://www.ncbi.nlm.nih.gov/genome/14568). The $S$. nigrocinctus aligned reads were then processed using the refmap.pl pipeline in STACKS 2.0. Filtering of the final set of SNPs was done using POPULATIONS module in STACKS 2.0 with the minimum percent of individuals genotyped at a locus in a population set at $10 \%$ and the minimum global minor allele frequency of SNPs set at 0.1 . Subsequent analysis was conducted using $\mathrm{R}$ statistical software (R Core Team 2016) using data in genepop format exported from POPULATIONS module.

CLUSTER analysis was conducted using package adegenet (Jombart et Devillard; 2010) and poppr (Kamvar et al., 2014, 2015) using all samples, including the seven remaining replicate pairs (one replicate was not recovered during sequencing) to select the optimal set of filters for removing individuals and loci based on the level of missing data. These filter settings were varied until the CLUSTER plot showed the paired replicates to be most closely related. This resulted in removal of loci which were absent in at least $15 \%$ of individuals and genotypes having more than $20 \%$ of total identified loci missing. For subsequent analyses, only one from each pair of replicate samples with the most loci was retained. We used the $\mathrm{R}$ package sequoia(Huisman, 2017) to identify related individuals, up to half - siblings; this program is specifically designed to use large SNP datasets and does not require a parent to be present in the sample. This was done for each of the two cohorts in order to make sure no related individuals were included in the Genome-Environment Association (GEA) tests.

We estimated the number of ancestral populations represented in the sample using the $L E A \mathrm{R}$ package (Frichot and François 2015). The analysis employed population clustering analysis with sparse non-negative matrix factorization optimization (sNMF) (Frichot et al. 2014) to estimate number of ancestral populations represented in the sample. The number of populations was determined from the cross entropy criteria and Cattell's rule (Cattell, 1966) from the sNMF output. We favored the sNMF routine because it is robust to departures from Hardy-Weinberg equilibrium as compared to Bayesian and Maximum Likelihood approaches (Frichot et al. 2014). We also compared the sNMF results to STRUCTURE 2.3.4 (Pritchard, Stephens \& Donnelly 2000) derived population clustering.

We examined whether selection pressure is consistent from year-to-year by testing for a difference in the number of private alleles, or homozygous loci in each year. The number of private alleles that were only found in 2014 but not in 2015 was quantified specifically to each sNMF derived population and across all SNPs. To compute whether the number of private alleles was significantly different between years, we needed to account for the difference in sample sizes between the years. We wrote a custom bootstrap routine in $\mathrm{R}$ to create a null distribution of the expected number of lost alleles in the smaller sample size by selecting without replacement from the larger year's sample, the reduced sample size. The significance $(\mathrm{p}=0.05)$ was then based on where the observed number of private alleles lies in the null distribution.

Latent factors mixed model (LFMM) algorithm in R package LEA(Frichot, 2014) was conducted to identify loci influenced by selection. For subsequent analysis we imputed any remaining missing data (3.5\% in 2014 and $4.1 \%$ in 2015). The missing genotypes were imputed using the random forest algorithm in the $\mathrm{R}$ packages randomForestSRC andradiator (Gosselin, 2018). We used the $\mathrm{R}$ package hierfstat(Goudet, 2005) to estimate pairwise $F_{S T}$ according to Nei (1987). Significance of $\mathrm{F}_{\mathrm{ST}}$ was calculated through 1,000 permutations of population indices. PCA analysis was conducted using the dudi.pca routine in ade4 R package (Dray 2007). 
Environmental variables included in the GEA included sample date and latitude, sea water temperature, and chlorophyll concentration. Phenotypic metrics were also included in the GEA, including percent lipid content and condition index. This analysis was done for 2014 and 2015 data separately with four latent factors to account for population structure while testing for genome-environment association. This was followed by nucleotide BLAST (https://blast.ncbi.nlm.nih.gov/Blast.cgi) search of nucleotide sequences and their corresponding protein coding gene regions where selection may be occurring. Loci annotation and BLAST searches of the associated 140 bp sequences were accepted when below the nucleotide and protein e-value threshold of $1 \times 10^{-10}$. BLAST e-value score is the probability that the similarity is due to chance.

The gene ontology (GO) enrichment analysis was used to determine whether the groups of genes associated with each of the environmental variables was enriched for certain biological processes. This analysis was done by querying geneontology.org database using zebra fish (Danio rerio ) as a reference organism, and the alpha level was set at $\mathrm{p}=0.05$ with no multiple test correction applied. Subsequently, the biocyc.org and informatics.jax.org were queried to determine general biological functions of the gene aggregates.

\section{3 | RESULTS}

\subsection{Bioinformatics and population grouping}

The total number of raw Illumina sequencing reads for the six plates was 2,983 million, or on average 497 million per plate. The proportion of reads with a correct barcode and restriction enzyme cut site varied from $69 \%$ to $83 \%$ per plate with an average of $76 \%$. Alignment to the S. nigrocinctus reference genome resulted in $79 \%$ overall alignment rate, with the percentage of aligned reads per sample ranging from 56 to $77 \%$ (mean $=71 \%$ ). Filtering of individuals with high percentages of missing genotypes $(>15 \%)$ and SNPs with low genotyping rates $(<20 \%)$ resulted in the final sample size of 398 individual fish (321 in 2014 and 77 in 2015) and 11,146 SNPs.

The ancestry analysis revealed the presence of 4 discrete spawning populations. sNMF ancestry analysis in LEA revealed 4 populations based on cross-entropy criteria (Figure $2 \mathrm{a}-2 \mathrm{~b}$ ). PCA analysis supported the $\mathrm{K}=4$ SNMF derived putative population clusters (Figure 2c). STRUCTURE (Pritchard et al. 2000) analysis also supported $\mathrm{K}=4$ populations, but with greater admixture of population 2 and 3 than was estimated via sNMF algorithm.All four of these populations were represented in both the 2014 and 2015 collections (Figure 3). Pairwise $F$ st values for genetic differentiation among putative population-year combinations revealed consistent differentiation between populations in each year (Table 1). Additionally, this difference was conserved across years, meaning little differentiation as measured by $F$ sT was observed within a population, between years. These findings support the results of the ancestry analysis and provide evidence that the 2014 and 2015 collections are composed of similar mixtures of discrete spawning populations.

Relatedness analysis showed no related individuals (up to half siblings) in the collections. This indicates that the discrete sNMF derived populations are not simply groups of closely related individuals. Furthermore, the results of this analysis ensured that no related individuals are included in the subsequent genotypeenvironment association models, which is thought to result in higher false positive rates due to lack of independence among the samples (Newman et al. 2001; Voight and Pritchard 2005).

Fewer private alleles were detected in 2015 than in 2014 and this pattern was significant when adjusting for the smaller sample size in 2015 (Table 2). This analysis was done separately for each sNMF-derived population, and we detected private alleles in common among all four populations (Table 3) indicating the same suite of alleles was not detected in 2015. This suggests that 2015 selection was stronger as compared to 2014, leading to loss of deleterious alleles in the 2015 cohort, which is consistent with the more abnormal oceanic conditions observed in 2015 than in 2014 (Cavole et al. 2016; Gentemann et al. 2017; Jones et al. 2018).

\section{2 | Genotype-environment association}

The results of LFMM analysis linking environmental and phenotypic variables to SNP variants indicated similar patterns of association with latitude and collection date in both years (Table 4). Of the 76 SNPs 
associated with these variables in 2014 and 305 in 2015, ten were shared between years (Supplementar materials, Table 1). The loci common in both years were significantly associated with latitude and collection date only. However, because of the sampling being conducted in a generally south to north direction, sampling date and latitude are collinear. This may possibly indicate a temporal gradient of selection where less fit individuals, those with deleterious alleles die off during their first months of life. Therefore the fish collected at later dates may be a subset of the fitter individuals as compared to earlier collections. Or there may be a true latitudinal gradient, or a combination of both factors contributing in various proportions to a selection gradient. Chlorophyll concentration and seawater temperature did not appear to influence loci in 2014, but were associated with 100 loci in 2015. It is important to note the Gulf of Alaska experienced unusually warm temperatures in 2015 (Cavole et al. 2016), marked by large sea bird die-offs (Jones et al. 2018).

In 2015, the fish experienced poorer growing condition as compared to 2014 (Cavole et al. 2016). This was evident in their weight for a given length when examining the condition index graphs (Figure 4). Linear regression analysis indicated a significantly $(\mathrm{p}<0.05)$ lower intercept and steeper slope in 2015 suggesting that smaller fish had poorer condition in 2015, but larger fish appeared to be unaffected. Whether the smaller fish died off and only larger fish survived is uncertain, although there appears to be a genetic basis of selection where a number of loci were identified as being associated with fish body condition (\% lipid and condition index). This was not observed for the fish collected in 2014 .

\section{3 | Gene ontology enrichment}

BLAST search resulted in only six loci being associated with known genes in 2014 and 24 in 2015 (Supplementary materials, Table 2). The broad-scale biological processes associated with the gene ontology (GO) enrichment are listed in (Supplementary materials, Table 3), while detailed information and fine-scale biological processes associated with the gene subsets may be found in the supplementary materials. The majority of genes were associated with developmental processes: 4 out 5 in 2014 and 108 out of 168 in 2015 (Supplementary materials, Table 3 ). Intracellular processes were associated with all environmental gradients in both years (see supplementary materials). Various developmental processes were mostly associated with collection date, chlorophyll-a concentration, latitude, water temperature, as well as tissue lipid percentage. Growth associated processes were mostly associated with chlorophyll-a concentration, collection date, collection latitude, water temperature and tissue lipid percent, but not condition index. Metabolic related processes were associated with condition index, latitude, and temperature. Fatty acid and lipid metabolism processes were only associated with a temperature gradient.

\section{4 | DISCUSSION}

\subsection{Sympatry and population structure}

One of the surprising findings of this study was the strong genetic clustering where the individuals of respective clusters were dispersed among the sampling locations, as well as conserved between the two years (Figure 3). This is consistent with the predictions from the DisMELS model (Stockhausen 2009), but in contrast with the findings of Kamin et al. (2014), where the collections were mapped to the closest adult groups and no genetic clustering was detected. However, their study only used twelve microsatellite markers and therefore may have lacked statistical power to detect the finer-scale genetic clustering as the RADseq approach we employed here. This inference is supported by the low $F_{S T}$ values detected here $\left(F_{S T}\right.$ ranging from 0.008 to 0.032 between clusters), because detection of low $F_{S T}$ values can require markers with high power. Also, the Kamin et al. (2014) study treated each haul collection as a sampling unit and conducted tests on the allele frequencies among the hauls, transects, locations, and years, but did not examine genetic clustering based on individual admixture analysis. However, the presence of genetic structure in our study is consistent with Palof et al. (2011), who detected isolation-by-distance population structure in the adults. The complete mixing among the genetically distinct groups of YOYs would be expected to result in a lack of population structure within just a few generations if the mixed fish maintained their grouping through settlement, recruitment and spawning. Our observations are consistent with both the DisMELS (Stockhausen 2009) and Palof et al. (2011) results indicating dispersal is not the primary mechanism by which POP 
population structure is maintained.

Our study suggests that distinct POP populations that are sympatric during the larval and YOY stage are likely geographically segregated and genetically differentiated during spawning. The presence of genetic clusters in spite of larval stage sympatry may indicate that once the fish settle out in the nearshore rearing habitat, they may be able to home-in to their natal locations over the following few years. If homing to their natal locations begins after fish settle out of the water column into their nearshore rearing habitat, then the mixtures of genotypes would be evident among larvae as they advected towards shore by cross-shelf currents.

The homing behavior in adult Sebastes spp. has been well documented (i.e. Carlson and Haight 1972; Matthews 1990; Carlson at al. 1995). It is unknown, however, when this behavior begins. Schools of age 1+ fish are spatially segregated (Carlson and Haight 1976), although it is unknown if those individuals are from a single or multiple source populations. It may be that these single cohort schools are composed of individuals from multiple sourced populations and like salmon, leave the school when natal location is nearby.

Homing behavior would result in genetic isolation and population structure consistent with our observations. Westrheim (1975) noted that POP schools were separated by bathymetry and would not cross deep trenches once in demersal stage. Withler et al. (2001) also described POP populations that were genetically distinct, yet lived within close proximity of each other, even when sampled in different seasons. Therefore if larvae from discrete nearby parturition locations, separated by bathymetric features such as canyons and ridges, were jointly entrapped in the oceanic currents, these clusters would resemble our observations. If homing to their natal locations begins after fish settle out of the water column into their nearshore rearing habitat, then the mixtures of genotypes would be evident among larvae as they advected towards shore by cross-shelf currents.

Another explanation for the fate of these YOY fish is that they are entrained in the coastal current and mesoscale eddies and fail to find suitable rearing habitat prior to winter settlement and are therefore destined to die, and our sampled fish were already the "swimming dead". The selection that we observed would then be the sign of various phenotypes dying at different rates, while the unobserved fish, the ones that did not get advected away from natal grounds and mixed with other similar-fated YOYs, are the only ones that successfully reach suitable nearby rearing habitat. Westrheim (1958), and Carlson and Haight (1976) noted the extreme successes and failures among POP year classes, which perhaps may be indicative of advection rate away from the natal grounds or high larval mortality, assuming consistent spawning population.

\section{2 | Genome environment association}

Fish employing broadcast spawning strategies characterized by larval and juvenile pelagic drift in ocean currents are subject to large interannual variability in oceanic conditions (Stockhausen et al., 2018). Stockhausen et al. (2018) refers to this as "running the gauntlet", as it is during this critical life stage that these fish are most vulnerable, experiencing the highest rates of mortality. This vulnerability is not only due to the vagaries of physical transport, but also due to their physiological condition where they must meet energetic demands of acquiring sufficient lipid reserves in order to move to inshore nursery areas.

During years favorable ocean conditions with ample food availability, such as 2014 for POP, mortality may be low and selection weak, allowing most phenotypes to survive through the pelagic phase and into nearshore settlement. However, during years of unfavorable ocean conditions, such as the unusual warming, low primary productivity, and low food availability in 2015 for POP, mortality may be high. If this increase in mortality is especially high for certain phenotypes, the selection may be strong, with only the most favorable phenotypes surviving to settlement.

Our results show consistent selective forces along the sampling date/latitude gradient in both 2014 and 2015 for POP with 10 of the 381 putative selective loci being in common in both years (Table 4). The LFMM analysis was done independently for each of the years and finding the same putative selected loci in both years is surprising. And although the LFMM method purportedly accounts for demographic factors such as population mixtures, the date/latitude gradient association could be due adult spawning populations being 
differentiated at these loci. Based on timing and location of spawning, their progeny may follow the spatiotemporal pattern identified by GEA. This is further supported by the distribution of the sNMF identified genetic clusters in relation to their distribution as seen in Figure 3. Alternatively, this may indicate that the spawning adult populations contain a high proportion of alleles at those loci that in 2014 and 2015 years were deleterious to the YOY progeny encountering the environmental conditions during their pelagic developmental stage. Since POP are very long-lived and may even spawn into their 100th year (Conrath and Knoth, 2013; Hulson et al., 2017; Heppell et al., 2010), some of the alleles in the parental population are expected to have been selectively advantageous during their respective first year at sea; therefore, the alleles that were advantageous when the parents were YOY may be deleterious in some oceanic conditions encountered by their progeny decades later. It is then expected that patterns of selection as displayed by the subsets of selected alleles would be cohort-specific.

Interannual differences in the strength of selection pressure was evident when comparing the 2014 and 2015 YOY POP fish. Due to the larger sample size in 2014 (321) than in 2015 (77), we would expect more putative selected loci in 2014 just due to the increase in statistical power, but that was not the case. In 2014, the oceanic conditions were typical (Cavole et al., 2016), with large YOY abundances in the ocean, and no putative selected loci were identified aside from those associated with collection date/latitude. However, in 2015, the oceanic conditions were abnormal with warmer sea surface temperatures (Gentemann et al., 2017) and were marked by large seabird die-off (Jones et al. 2018). This likely resulted in stronger selective pressure on YOY in 2015 and this is supported by the greater number of putative selected alleles. Therefore by the time the 2014 and 2015 cohorts settled out in the nearshore, we expect that most individuals have gene variants that were most favorable and selected for by the conditions encountered in that year.

The difference in the change in condition index indicates different growth conditions between the two years. In 2015, the smaller fish had less mass than in 2014, but the larger fish had equivalent mass in both years (Figure 4). This indicates that in 2015, a much warmer year than in 2014, the smaller fish were unable to gain weight as compared to the same sized fish in 2014. If the temperatures were still within optima for POP YOY growth, then smaller size suggests smaller-sized prey items were either unavailable or of insufficient nutritional value to support the higher growth rates predicted by the higher temperature in 2015. However the larger fish in both years were equally successful at gaining mass. This suggests that the environment in 2015 imposed a larger variance in fitness and therefore much stronger selection pressure, and this is consistent with the greater number of putative selected loci in 2015 than in 2014. This is further supported by the recruitment estimates in the 2017 stock assessment with 2014 cohort being 87.5 million and 38.2 million in 2015 (Hulson et al., 2017).

\subsection{Gene ontology enrichment}

The GO enrichment analysis yielded particularly interesting and intuitive results. The selective processes identified here act during the developmental and high growth larval life stage, and $87 \%$ of the general biological processes associated with the LFMM identified putative selected genes directly corresponded to development and growth. The remaining $7 \%$ and $5 \%$ were associated with intracellular processes and metabolism respectively. Furthermore, in 2014, we did not identify any biological processes associated with growth or metabolism, indicating that the early life conditions were favorable across the habitat surveyed, with little selection acting on those gene variants. The numerous processes identified in 2015, however, may be indicative of unfavorable oceanic conditions, leading to a significant loss of phenotypes with the deleterious gene variants. Because 2015 was an unusually warm year (Gentemann et al., 2017), it is not surprising that these warmer temperatures would directly affect metabolic processes. This is underscored by our finding of associations between fatty acid, lipid metabolism, and temperature for 2015, but not for 2014 .

\subsection{Fluctuating selection and maintenance of adaptive diversity}

Our results suggest the presence of a temporal portfolio effect, where a multi-age population with overlapping generations maintains a portfolio of genotypes (Ellner and Hairston 1994). The interannual variation in oceanic conditions and its effects on the selection of POP during their first year at sea prior to settlement may 
be thought of as a "Selective Sieve" (Figure 5), where each year presents different sets of selection pressures during the early developmental life stage. The selection pressures, in the form of various environmental drivers such as ocean temperatures, productivity (chlorophyll-a) and their timing vary from year to year resulting in some phenotypes being detrimental in one year, but advantageous in another when encountering highly diverse pelagic habitats. The selective sieve is therefore specific to the year of the POP pelagic life stage, and therefore unique to each cohort which then contains alleles favored by the conditions of their first year. In these long-lived species with lifespans of over 100 years, in any one year the larval cohort at parturition may be the result of breeding across dozens of spawning aged cohorts ( 8 to 100 years old or more). The parental cohorts contain many alleles that are representative of the selection due to oceanic conditions during their first year at sea. At parturition, the POP larvae contain all of these alleles, however, from parturition to settlement, some of the alleles prove to be deleterious as the oceanic conditions do not favor them, and only a subset of the larvae containing the advantageous alleles survive until settlement. This is an example of fluctuating selection (Bell 2010; Kawecki 2000; Lande 2007), where the direction of selection is constantly changing between generations. The species' life history of long reproductive period relative to the time-scale of fluctuating selection maintains genetic diversity that is adaptive across a range of environmental variation.

Population viability in fish employing broadcast spawning strategies is especially vulnerable to changing oceanographic conditions. Ocean currents may advect YOY far offshore where they will fail to reach their shelf-slope nursery areas. Using ROMS-based models, Stockhausen et al. (2018) showed that up to $70 \%$ of the YOY failed to reach suitable nursery habitats prior to wintertime and were not expected to survive. The ones that are not advected out of reach of nursery habitat must still acquire sufficient lipid reserves in order to settle out and overwinter. Interannual differences in ocean temperatures, prey and predator abundances and composition will also affect whether the YOY will survive to reach their nursery habitats with sufficient lipid reserves to overwinter and eventually recruit to the population. Maintaining a high diversity in phenotypes through cohort-specific selection may be thought of as a form of diversification bet hedging response to a fluctuating natural selection as described by Simons (2009).

These results underscore the importance of maintaining many cohorts in order to maximize the population resilience to environmental variability. POP are vulnerable to age truncation where older fish are more likely to be fished since they are exposed to fishing longer (Berkeley 2004). The importance of maintaining older age classes in marine fishes has long been recognized as being a factor in their recruitment (Longhurst, 2002; Hixon et al., 2013). Hanselman et al. (2005) noted that age truncation has occurred in POP due to unrestricted fishing in the past which led to disproportional absence of $40+$ year old fish. However, the mechanism of adaptation through maintenance of age-specific advantageous alleles would be compromised if whole cohorts are inadvertently fished by depriving populations of the advantageous alleles specific to that cohort.

The uniqueness of the demonstrated cohort-specific selection signatures may allow for reconstruction of past oceanographic conditions based on the alleles present in a given cohort. The 2015 cohort will therefore represent the alleles favored (or conversely lost) during especially warm oceanic conditions as experienced during 2015. It may be possible that by examining allele frequencies in an adult cohort, of for example 50-year-old fish, the selection pressures encountered during their YOY stage may be revealed. Furthermore, ageing of adults based on cohort-specific allelic signatures may also be possible by maintaining cohort-specific selected allelic signatures. This may prove especially useful since otolith ageing of POP adults is fairly error prone especially for older fish (>20 years old) (Beamish, 1979; Stanley, 1986).

\section{5 | Conclusions}

We found evidence for different selective pressures for POP YOY across two different years that had very different environmental conditions. These results provide evidence that long-lived marine species such as POP may be resilient to natural environmental variability by maintaining a portfolio of adaptive alleles resulting from selection encountered by each cohort during their most vulnerable life stage from parturition to settlement. However, this resilience may be limited to the environmental conditions that prevailed in the 
last few centuries. The "selective sieve" framework may provide valuable insights into other species employing similar life history strategies. Hoffman and Sgro (2011) note that species facing strong but fluctuating selection pressures, such as YOY POP during the pelagic life stage, will have a difficult time adapting. Here, we demonstrated an exception where due to the way POP are able to maintain these selected alleles may allow them to be especially adaptable under fluctuating environmental conditions. POP have proven to be an ideal model species for investigating portfolio effects. By examining relative strengths of selection among discrete populations and adult cohorts, it allows us to jointly examine spatial and temporal portfolio effects. In the future, we plan to sample across adult populations to link genetic variation to larval cohorts and adult habitat/geographic population structure.

\section{ACKNOWLEDGMENTS}

This work was supported by the Bioinformatics and Computational Biology Program at the University of Idaho (BCB fellowship), an Institutional Development Award (IDeA) from the National Institute of General Medical Sciences of the National Institutes of Health under grant number P30 GM103324, and NOAA internal funding.

\section{REFERENCES}

Alexander, D.H., Novembre, J. \& K. Lange. (2009). Fast model-based estimation of ancestry in unrelated individuals. Genome Research, 19:1655-1664.

Ali, O.A., O'Rourke S.M., Amish, S.J., Meek, M.H., Gordon, L., Carson, J. and Miller, M. R. (2016). RAD Capture (Rapture): Flexible and efficient sequence-based genotyping. Genetics 202(2): 389-400.

Andrews, K., Good, J., Miller, M, Luikart, G, \& Hohenlohe, P. (2016). Harnessing the power of RADseq for ecological and evolutionary genomics. Nature Reviews Genetics 17, 81-92.

Andrews, K.R., Adams J, Cassirer F, Plowright R, Gardner C, Dwire M, Hohenlohe PA, \& Waits L. (2018). A bioinformatic pipeline for identifying informative SNP panels for parentage assignment from RADseq data. Molecular Ecology Resources 18: 1263-1281.

Barrio, A.M., Lamichhaney, S., Fan, G., Rafati, N., Pettersson, M., Zhang, H., Dainat, J., Ekman, D., Höppner, M., Jern, P. \& Martin, M., (2016). The genetic basis for ecological adaptation of the Atlantic herring revealed by genome sequencing. eLife 2016;5:e12081.

Beamish, R. J. (1979). New information on the longevity of Pacific ocean perch (Sebastes alutus ). Journal of the Fisheries Board of Canada, 36(11), 1395-1400.

Bell, G. (2010). Fluctuating selection: the perpetual renewal of adaptation in variable environments. Philosophical Transactions of the Royal Society B: Biological Sciences, 365(1537), 87-97.

Berkeley, S. A., Hixon, M. A., Larson, R. J., \& Love, M. S. (2004). Fisheries sustainability via protection of age structure and spatial distribution of fish populations. Fisheries, 29(8), 23-32.

Brendonck L, De Meester L. 2003. Egg banks in freshwater zooplankton: evolutionary and ecological archives in the sediment. Hydrobiologia, 491: 65-84.

Carlson, H. R., \& Haight, R. E. (1972). Evidence for a home site and homing of adult yellowtail rockfish, Sebastes flavidus . Journal of the Fisheries Board of Canada, 29(7), 1011-1014.

Carlson, H. R., \& Haight, R. E. (1976). Juvenile life of Pacific ocean perch, Sebastes alutus, in coastal fiords of southeastern Alaska: Their environment, growth, food habits, and schooling behavior. Transactions of the American Fisheries Society, 105(2): 191-201.

Carlson, H. R., Haight, R. E., \& Helle, J. H. (1995). Initial behavior of displaced yellowtail rockfish Sebastes flavidus in Lynn Canal, Southeast Alaska. Alaska Fisheries Research Bulletin, 2(1): 76-80.

Cattell, R. B. (1966). The scree test for the number of factors. Multivariate Behavioral Research, 1, 245-276. 
Catchen, J.M., Hohenlohe, P.A., Bassham, S, Amores, A, Cresko, WA. (2013). Stacks: an Analysis tool set for population genomics. Molecular Ecology 22: 3124-3140.

Catchen, J., Hohenlohe, P.A., Bernatchez, L., Funk, W.C., Andrews, K.R., \& Allendorf, F. (2017). Unbroken: RADseq remains a powerful tool for understanding the genetics of adaptation in natural populations. Molecular Ecology Resources 17: 362-365

Cavole, L. M., Demko, A. M., Diner, R. E., Giddings, A., Koester, I., Pagniello, C. M., Paulsen, M-L., Ramirez-Valdez, A., Schwenck, S. M., Yen, N. K., Zill, M. E., \& Franks, P. J. S. (2016). Biological impacts of the 2013-2015 warm-water anomaly in the Northeast Pacific: winners, losers, and the future. Oceanography, 29(2), 273-285.

Chabrol, E., Charonnet R (1937) Une novelle reaction pour l'etude des lipides. Presse Med 45:1713

Conrath, C. L., \& Knoth, B. (2013). Reproductive biology of Pacific ocean perch in the Gulf of Alaska. Marine and Coastal Fisheries, 5(1), 21-27.

Cure, K., Thomas, L., Hobbs, J. P. A., Fairclough, D. V., \& Kennington, W. J. (2017). Genomic signatures of local adaptation reveal source-sink dynamics in a high gene flow fish species. Scientific Reports, 7(1), 8618.

Davey, J. W., \& Blaxter, M. L. (2010). RADSeq: next-generation population genetics. Briefings in Functional Genomics, 9(5-6), 416-423.

Dray S, Dufour A (2007). The ade4 package: Implementing the duality diagram for ecologists. Journal of Statistical Software, 22(4), 1-20. doi: 10.18637/jss.v022.i04.

Ellner S, Hairston NG. 1994. Role of overlapping generations in maintaining genetic variation in a fluctuating environment. The American Naturalist, 143: 403-417.

Folch, Jordi, M. Lees, \& G. H. Sloane Stanley. (1957). A simple method for the isolation and purification of total lipides from animal tissues. Journal of Biological Chemistry, 226(1): 497-509.

Frichot, E., Mathieu, F., Trouillon, T., Bouchard, G., \& François, O. (2014). Fast and efficient estimation of individual ancestry coefficients. Genetics, 196(4), 973-983.

Frichot E, Francois O. (2015). LEA: an R package for landscape and ecological association studies. Methods in Ecology and Evolution 6: 925-929.

Froese, R. (2006). Cube law, condition factor and weight-length relationships: History, meta-analysis and recommendations. Journal of Applied Ichthyology 22(4): 241-253.

Garvin, M.R., Marcotte, R.W., Palof, K.J., Riley, R.J., Kamin, L.M. \& Gharrett, A.J. (2011) Diagnostic single nucleotide polymorphisms (SNPs) identify Pacific ocean perch and delineate blackspotted and rougheye rockfish. Trans. Am. Fish. Soc. 140:984-988.

Gentemann, C. L., Fewings, M. R., \& Garcia-Reyes, M. (2017). Satellite sea surface temperatures along the West Coast of the United States during the 2014-2016 northeast Pacific marine heat wave. Geophysical Research Letters, 44(1), 312-319.

Gosselin, T. (2018) radiator: RADseq data exploration, manipulation and visualization using R. R package version 0.0.11. Retrieved from https://github.com/thierrygosselin/radiator.

Goudet, J. (2005). Hierfstat, a package for R to compute and test hierarchical F-statistics. Molecular Ecology Notes, 5(1), 184-186.

Groot, C., \& Margolis, L. (Eds.). (1991). Pacific salmon life histories. UBC Press. 608 p.

Hanselman, D., Heifetz, J., Fujioka, J. T., \& Ianelli, J. N. (2005). Gulf of Alaska Pacific ocean perch. Stock assessment and fishery evaluation report for the groundfish fisheries of the Gulf of Alaska, 525-578. In Stock 
Assessment and Fishery Evaluation Report for the Groundfish Resources of the Gulf of Alaska. North Pacific Fishery Management Council, 605W. 4th Ave., Suite 306, Anchorage, AK 99501-2252.

Heppell, S. S., Heppell, S. A., Spencer, P. D., Smith, W. D., \& Arnold, L. (2010). Assessment of female reproductive effort and maternal effects in Pacific ocean perch Sebastes alutus : Do big old females matter? North Pacific Research Board Final Report, NPRB Project 629. Oregon Sea Grant College Program.

Hixon, M. A., Johnson, D. W., \& Sogard, S. M. (2013). BOFFFFs: on the importance of conserving old-growth age structure in fishery populations. ICES Journal of Marine Science, 71(8), 2171-2185.

Hoey, A. S., \& McCormick, M. I. (2004). Selective predation for low body condition at the larval-juvenile transition of a coral reef fish. Oecologia 139(1):23-29.

Hoffmann, A. A., \& Sgro, C. M. (2011). Climate change and evolutionary adaptation. Nature, 470(7335), 479.

Huisman, J. (2017). Pedigree reconstruction from SNP data: parentage assignment, sibship clustering and beyond. Molecular Ecology Resources, 17(5): 1009-1024. R package version 1.0.2, Retrieved from https://github.com/JiscaH/sequoia.

Hulson, P.J., Hanselman, D.H., Lunsford, C.R. and Fissel, B. (2017). Assessment of the Pacific Ocean perch stock in the Gulf of Alaska. P. 913-992. In Stock Assessment and Fishery Evaluation Report for the Groundfish Resources of the Gulf of Alaska. North Pacific Fishery Management Council, 605W. 4th Ave., Suite 306, Anchorage, AK 99501-2252.

Jasonowicz, A.J., Goetz, F.W., Goetz, G.W. \& Nichols, K.M. (2016). Love the one you're with: Genomic evidence of panmixia in the sablefish (Anoplopoma fimbria). Canadian Journal of Fisheries and Aquatic Sciences, 999:1-11.

Jombart T., Devillard S., \& Balloux F. (2010) Discriminant analysis of principal components: a New method for the analysis of genetically structured populations. BMC Genetics 11:94

Jones, T., Parrish, J. K., Peterson, W. T., Bjorkstedt, E. P., Bond, N. A., Ballance, L. T., Bowes, V. J., Hipfner, M., Burgess, H. K., Dolliver, J. E., Lindquist, K., Lindsey, J., Nevins, H. M., Robertson, R. R. Roletto, J., Wilson, L., Joyce, T., \& J. Harvey. (2018). Massive mortality of a planktivorous seabird in response to a marine heatwave. Geophysical Research Letters, 45(7), 3193-3202.

Kamin, L. M., Palof, K. J., Heifetz, J., \& Gharrett, A. J. (2014). Interannual and spatial variation in the population genetic composition of young-of-the-year Pacific ocean perch (Sebastes alutus ) in the Gulf of Alaska. Fisheries Oceanography, 23(1), 1-17.

Kamvar, Z. N., Tabima, J.F., Grunwald, N.J. (2014) Poppr: an R package for genetic analysis of populations with clonal, partially clonal, and/or sexual reproduction. PeerJ 2:e281. https://doi.org/10.7717/peerj.281.

Kamvar Z. N., Brooks JC \& Grunwald NJ (2015) Novel R tools for analysis of genome-wide population genetic data with emphasis on clonality. Front. Genet. 6:208.

Kawecki, T. J. (2000). The evolution of genetic canalization under fluctuating selection. Evolution, 54(1), $1-12$.

Kendall, A.W., Kondzela, C., Li, Z., Clausen, D. \& Gharrett, A.J. (2007) Genetic and morphological identification of pelagic juvenile rockfish collected from the Gulf of Alaska. U.S. Department of Commerce, NOAA Professional Paper NMFS 9, 26 p.

Kumar, G., \& Kocour, M. (2017). Applications of next-generation sequencing in fisheries research: a Review. Fisheries Research, 186, 11-22.

Lande, R. (2007). Expected relative fitness and the adaptive topography of fluctuating selection. Evolution, 61(8), 1835-1846. 
Langmead B, \& Salzberg S. (2012) Fast gapped-read alignment with Bowtie 2. Nature Methods. 9:357-359. Levin, P.S, \& C. Mollmann C. (2015) Marine ecosystem regime shifts: challenges and opportunities for ecosystem-based management. Philosophical Transactions of the Royal Society B: Biological Sciences. 370(1659):20130275.

Link, J.S. (2002) What does ecosystem-based fisheries management mean. Fisheries, 27(4):18-21.

Longhurst, A. (2002). Murphy's Law revisited: Longevity as a factor in recruitment to fish populations. Fisheries Research, 56(2), 125-131.

Love, M. S., Yoklavich, M., \& Thorsteinson, L. K. (2002). The Rockfishes of the Northeast Pacific. University of California Press. 416 p.

Major, R. L., and H. H. Shippen. (1970). Synopsis of biological data on Pacific ocean perch, Sebastodes alutus. FAO Fisheries Synopsis No. 79, NOAA Circular 347, 38 p.

Manel, S., Gaggiotti, O. E., \& Waples, R. S. (2005). Assignment methods: Matching biological questions with appropriate techniques. Trends in Ecology \& Evolution, 20(3), 136-142.

Marshall, T. C., Slate, J. B. K. E., Kruuk, L. E. B., \& Pemberton, J. M. (1998). Statistical confidence for likelihood-based paternity inference in natural populations. Molecular Ecology, 7(5), 639-655.

Matthews, K. R. (1990). A telemetric study of the home ranges and homing routes of copper and quillback rockfishes on shallow rocky reefs. Canadian Journal of Zoology, 68(11), 2243-2250.

McKinney, G. J., Larson, W. A., Seeb, L. W. \& Seeb, J. E. (2017), RADseq provides unprecedented insights into molecular ecology and evolutionary genetics: comment on Breaking RAD by Lowry et al. (2016). Mol Ecol Resour, 17: 356-361. doi:10.1111/1755-0998.12649.

Megrey, B. A. (1988). Review and comparison of age-structured stock assessment models. NWAFC Processed Rep., 88-21, 116 p. Northwest and Alaska Fish. Cent., Natl. Mar. Fish. Serv., NOAA, 7600 Sand Point Way NE, Seattle, WA 98115-0070.

Narum, S. R., Buerkle, C. A., Davey, J. W., Miller, M. R., \& Hohenlohe, P. A. (2013). Genotyping-bysequencing in ecological and conservation genomics. Molecular Ecology, 22(11), 2841-2847.

Nei, M. (1987). Molecular Evolutionary Genetics. Columbia University Press. 512 p.

NOAA (2019). Commercial Fishery Statistics - Annual Commercial Landings by Group: https://www.fisheries.noaa.gov/national/sustainable-fisheries/commercial-fisheries-landings

Newman, D. L., Abney, M., McPeek, M. S., Ober, C., \& Cox, N. J. (2001). The importance of genealogy in determining genetic associations with complex traits. The American Journal of Human Genetics, 69(5), 1146-1148.

Pacifici, M., Foden, W. B., Visconti, P., Watson, J. E., Butchart, S. H., Kovacs, K. M., Scheffers, B. R., Hole, D. G., Martin, T. G., Akcakaya, H. R., Corlett, R. T., Huntley, B., Bickford, D., Carr, J. A., Hoffmann, A. A., Midgley, G. F., Pearce-Kelly, P., Pearson, R. G., Williams, S. E., Willis, S. G. Young, B., \& Rondinini, C. (2015). Assessing species vulnerability to climate change. Nature Climate Change, 5(3), 215.

Palof, K.J., Heifetz, J., \& Gharrett, A.J. (2011). Geographic structure in Alaskan Pacific ocean perch (Sebastes alutus ) indicates limited life-time dispersal. Mar. Biol. 158:779-792.

Parker, S.J., Berkeley, S.A., Golden, J.T. et al (2000). Management of Pacific rockfish. Fisheries 25:22-29

Pritchard, J. K., Stephens, M., \& Donnelly, P. (2000). Inference of population structure using multilocus genotype data. Genetics, 155(2), 945-959.

R Core Team (2016). R: A language and environment for statistical computing. R Foundation for Statistical Computing, Vienna, Austria. URL https://www.R-project.org/. 
Moss, J. H., Shotwell, S. K., Heintz, R. A., Atkinson, S., Debenham, C., Fournier, W., Golden, N., Heifetz, J., Mueter, F. J., Pirtle, J. L., Reid, J. A., Slater, L., Sreenivasan, A., Will, A., Zaleski, M., \& Zimmermann, M. (2016). Surviving the Gauntlet: A comparative study of the pelagic, demersal, and spatial linkages that determine groundfish recruitment and diversity in the Gulf of Alaska ecosystem (NPRB GOA Project G81 Upper Trophic Level Final Report). North Pacific Research Board, Anchorage, AK.

Rooper, C. N., Boldt, J. L., Batten, S., \& Gburski, C. (2012). Growth and production of Pacific ocean perch (Sebastes alutus ) in nursery habitats of the Gulf of Alaska. Fisheries Oceanography, 21(6), 415-429.

Saenz-Agudelo, P., Jones, G. P., Thorrold, S. R., \& Planes, S. (2009). Estimating connectivity in marine populations: an Empirical evaluation of assignment tests and parentage analysis under different gene flow scenarios. Molecular Ecology, 18(8), 1765-1776.

Schindler, D. E., Hilborn, R., Chasco, B., Boatright, C. P., Quinn, T. P., Rogers, L. A., \& Webster, M. S. (2010). Population diversity and the portfolio effect in an exploited species. Nature, 465(7298), 609.

Sigler, M. F., M. P. Eagleton, T. E. Helser, J. V. Olson, J. L. Pirtle, C. N. Rooper, S. C. Simpson, \& R. P. Stone. (2017). Alaska Essential Fish Habitat Research Plan: A Research Plan for the National Marine Fisheries Service's Alaska Fisheries Science Center and Alaska Regional Office. AFSC Processed Rep. 201505, 22 p. Alaska Fish. Sci. Cent., NOAA, Natl. Mar. Fish. Serv., 7600 Sand Point Way NE, Seattle WA 98115 .

Simons, A. M. (2009). Fluctuating natural selection accounts for the evolution of diversification bet hedging. Proceedings of the Royal Society B: Biological Sciences, 276(1664), 1987-1992.

Stanley, R. D. (1986). A comparison of age estimates derived from the surface and cross-section methods of otolith reading for Pacific ocean perch (Sebastes alutus ), p. 187-196. In Proceedings of the International Rockfish Symposium. Alaska Sea Grant College Program, AK-SG-87-02.

Stockhausen, W. T., \& Hermann, A. J. (2007). Modeling larval dispersion of rockfish: a Tool for marine reserve design. Biology, assessment, and management of North Pacific rockfishes, 251-273.Alaska Sea Grant College Program, AK-SG-07-01.

Stockhausen, B. (2009). DisMELS: A Dispersal Model for Early Life History Stages. http://www.afsc.noaa.gov/Quarterly/jfm2009/divrptsREFM5.htm. Last accessed July 25, 2016.

Stockhausen, W. T., Coyle, K. O., Hermann, A. J., Doyle, M., Gibson, G. A., Hinckley, S., Ladd, C., \& Parada, C. (2018). Running the gauntlet: Connectivity between natal and nursery areas for Pacific ocean perch (Sebastes alutus ) in the Gulf of Alaska, as inferred from a biophysical individual-based model. Deep-sea Research Part II: Topical Studies in Oceanography, 165:74-88.

Sunday, J. M., Crim, R. N., Harley, C. D., \& Hart, M. W. (2011). Quantifying rates of evolutionary adaptation in response to ocean acidification. PLOS ONE, 6(8), e22881.

Valenzuela-Quinonez, F., (2016). How fisheries management can benefit from genomics? Briefings in Functional Genomics, 15(5): 352-357. p.elw006.

Voight, B. F., \& Pritchard, J. K. (2005). Confounding from cryptic relatedness in case-control association studies. PLOS Genetics. https://doi.org/10.1371/journal.pgen.0010032.

Wang, H.-Y., \& Hook, T. O. (2009). Eco-genetic model to explore fishing-induced ecological and evolutionary effects on growth and maturation schedules. Evolutionary Applications, 2(3), 438-455.

Wenne, R., Boudry, P., Hemmer-Hansen, J., Lubieniecki, K.P., Was, A., \& Kause, A. (2007). What role for genomics in fisheries management and aquaculture? Aquat. Living Resour., 203 241-255.

Westrheim, S. J. (1958). On the biology of the Pacific ocean perch,Sebastodes alutu s (Gilbert) (Doctoral dissertation, University of Washington). 
Westrheim, S. J. (1975). Reproduction, maturation, and identification of larvae of some Sebastes (Scorpaenidae) species in the northeast Pacific Ocean. Journal of the Fisheries Board of Canada, 32(12), 23992411.

Withler, R., Beacham, T., Schulze, A., Richards, L., \& Miller, K. (2001). Co-existing populations of Pacific ocean perch, Sebastes alutus, in Queen Charlotte Sound, British Columbia. Marine Biology, 139(1), 1-12.

\section{Data Accessibility}

The data that support the findings of this study will be openly available. The raw sequence data will be deposited at publicly accessible database such as Dryad, NCBI prior to publication.

\section{Author Contributions}

J.M. conceived the study, generated the genomic data, conducted analysis and wrote the paper. K.R.A. oversaw generation of genomic data and assisted in bioinformatics processing. P.A.H. oversaw genomic data production and bioinformatics.

\section{Tables and Figures}

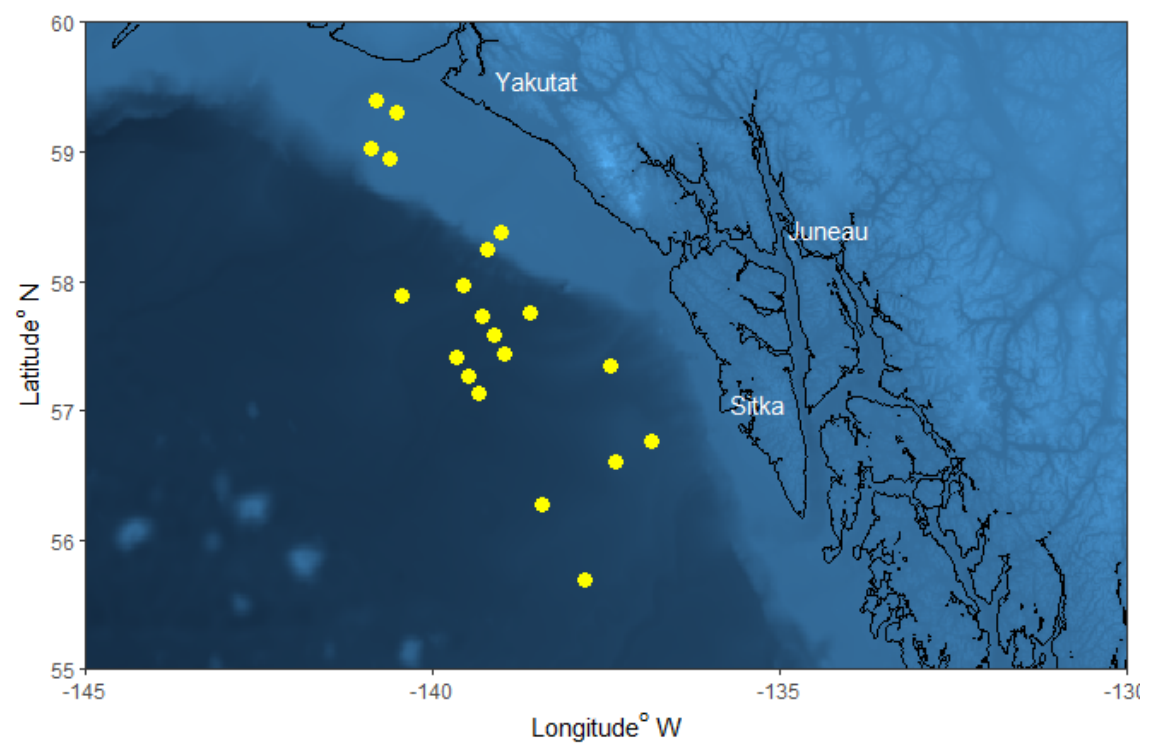

$+$

Figure 1. Locations of the 2014 (yellow) and 2015 (orange) collection of the young-of-the-year Pacific ocean perch. 


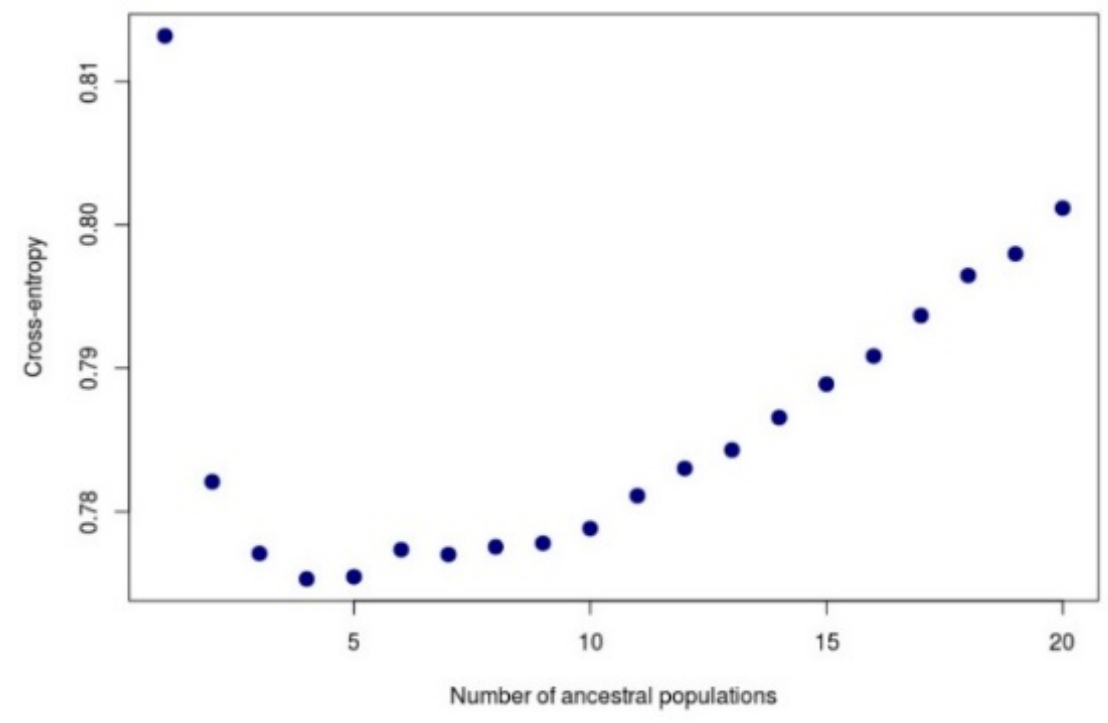

Figure 2. sNMF ancestry analysis revealed 4 ancestral populations represented by fish collected in both 2014 and 2015: (a) cross-entropy plot for the number of populations in sample; (b) sNMF population ancestry barplot; and (c) PCA analysis with the colors corresponding to the sNMF-derived majority ancestry populations in panel b. Note that both years were included concurrently in the analysis. For clarity year designation is omitted as each population cluster contains both years interspersed throughout.

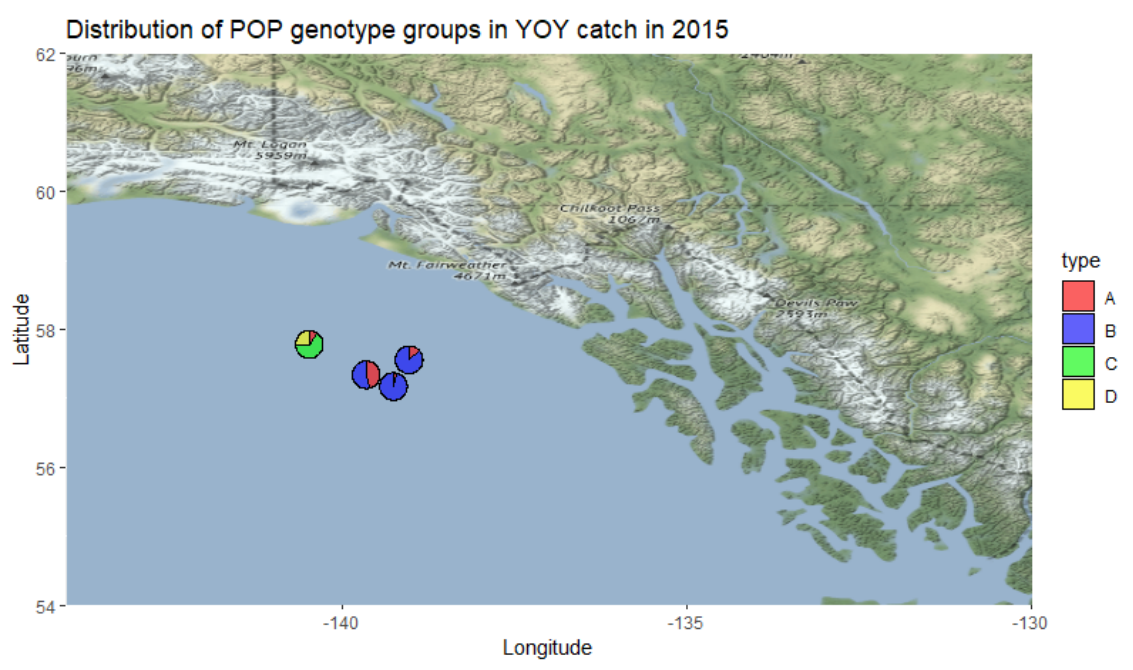

Figure 3. Spatial distribution and the proportional representation of the putative populations in the samples in 2014 (a) and 2015 (b) collections. 


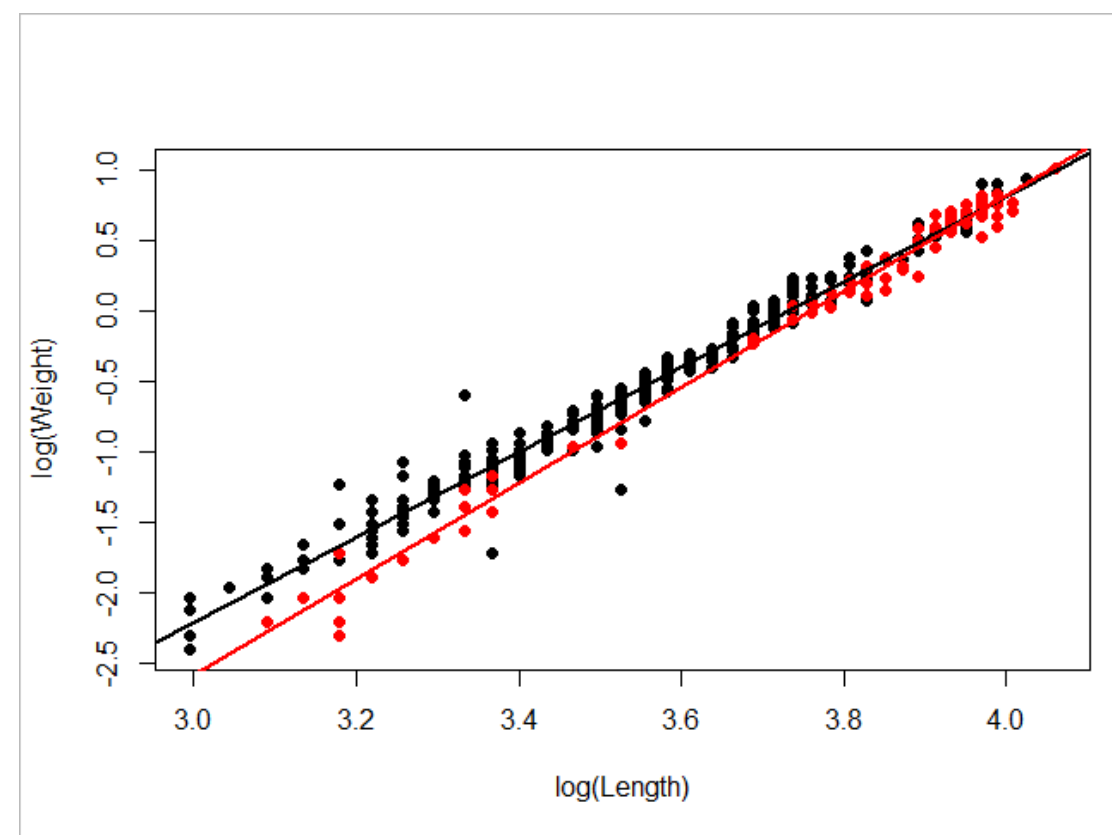

Figure 4. Relationships of body length and weight in the 2014 (black and 2015 (red) young-of-the-year Pacific ocean perch. In 2015, smaller length fish had significantly $(\mathrm{p}<0.0001)$ smaller mass than in 2014, indicating environmental factors in 2015 may have negatively influenced their condition.
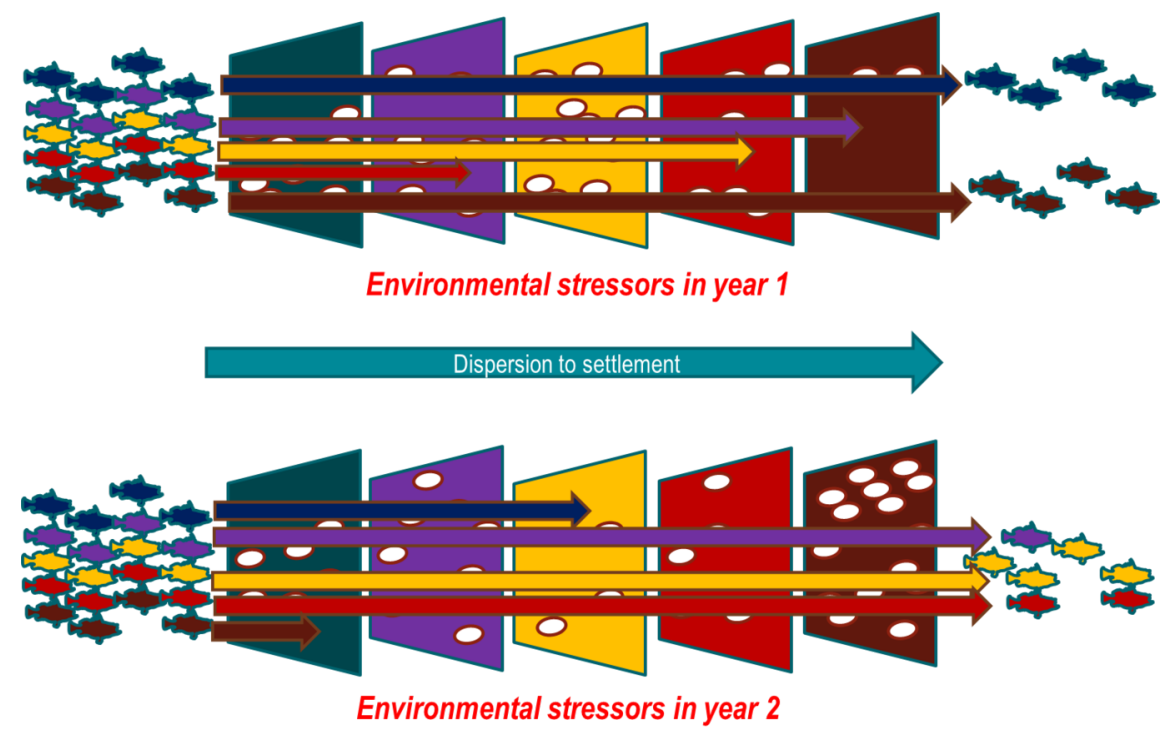

Figure 5. The selective sieve. The five colored plates represent various hypothetical environmental forces (such as temperature, chlorophyll density, etc), that are highly variable among years. This represent the different selection pressures encountered by the Pacific Ocean Perch during initial pelagic life stage. Each years' cohort therefore contains the alleles that were selected for during their first year. Populations of longlived adults representing multiple cohorts maintain genetic diversity as a result of this temporal variation in selection. 
Table 1. Pairwise $F_{S T}$ values $\left(F_{S T}\right.$ below diagonal and p-value above the diagonal) between sNMF-derived populations and sampling year. There is little genetic differentiation as indicated by $\boldsymbol{F}_{\mathrm{ST}}$ within a population between years (bolded $\boldsymbol{F}_{\mathrm{ST}}$ and corresponding p-values).

\begin{tabular}{lllllllll}
\hline & $2014-\mathrm{A}$ & $2014-\mathrm{B}$ & $2014-\mathrm{C}$ & $2014-\mathrm{D}$ & $2015-\mathrm{A}$ & $2015-\mathrm{B}$ & $2015-\mathrm{C}$ & $2015-\mathrm{D}$ \\
\hline $2014-\mathrm{A}$ & $*$ & 0.001 & 0.001 & 0.001 & $\mathbf{0 . 0 2 1}$ & 0.001 & 0.001 & 0.001 \\
$2014-\mathrm{B}$ & 0.023 & $*$ & 0.001 & 0.001 & 0.001 & $\mathbf{0 . 3 2 9}$ & 0.001 & 0.001 \\
$2014-\mathrm{C}$ & 0.030 & 0.014 & $*$ & 0.001 & 0.001 & 0.001 & $\mathbf{0 . 4 8 4}$ & 0.001 \\
$2014-\mathrm{D}$ & 0.023 & 0.009 & 0.012 & $*$ & 0.001 & 0.011 & 0.001 & $\mathbf{0 . 3 0 3}$ \\
$2015-\mathrm{A}$ & $\mathbf{0 . 0 0 1}$ & 0.026 & 0.032 & 0.026 & $*$ & 0.001 & 0.001 & 0.001 \\
$2015-\mathrm{B}$ & 0.023 & $\mathbf{0 . 0 0 0}$ & 0.013 & 0.007 & 0.026 & $*$ & 0.001 & 0.017 \\
$2015-\mathrm{C}$ & 0.030 & 0.014 & $\mathbf{0 . 0 0 0}$ & 0.011 & 0.032 & 0.013 & $*$ & 0.001 \\
$2015-\mathrm{D}$ & 0.023 & 0.009 & 0.011 & $\mathbf{0 . 0 0 0}$ & 0.026 & 0.008 & 0.012 & $*$ \\
\hline
\end{tabular}

Table 2 Number of private alleles in the given year specific to each sNMF-derived population. Private alleles is the number of alleles that were detected in only one year. For example, 127 is the number of alleles detected in population $A$ in 2014, but not in 2015 .

\begin{tabular}{lllll}
\hline & Sample Size & Sample Size & Private Alleles & Private Alleles \\
\hline Population & 2014 & 2015 & 2014 & 2015 \\
A & 100 & 47 & 127 & $1^{1}$ \\
B & 103 & 5 & 2,101 & $0^{1}$ \\
C & 19 & 12 & 604 & $149^{1}$ \\
D & 99 & 13 & 401 & 4 \\
\hline
\end{tabular}

${ }^{1}$ Indicates that there are significantly fewer alleles lost in 2015 than expected by chance.

Table 3. Number of private alleles in common between the sNMF-derived populations that were detected in 2014 samples but not in 2015. For example, 30 is the number of alleles detected in 2014 in both populations $\mathrm{A}$ and $\mathrm{B}$, that were not detected in 2015 in either A or B population

\begin{tabular}{llll}
\hline Population & A & B & C \\
\hline B & 30 & & \\
C & 4 & 181 & \\
D & 5 & 180 & 74 \\
\hline
\end{tabular}

Table 4. Results of LFMM analysis and the number of putative loci under divergent selection in 2014 and 2015. Note that sampling date and latitude (both are confounded as sampling was generally in the northward direction) were consistently associated with selection pressure in both years. However, other environmental factors only showed signatures of selection in 2015 .

\begin{tabular}{lll}
\hline & Selected Loci & Selected Loci \\
\hline Gradient & $\mathbf{2 0 1 4}$ & $\mathbf{2 0 1 5}$ \\
Latitude & 14 & 56 \\
Sampling date & 62 & 101 \\
Temperature & 0 & 16 \\
Chlorophyll & 0 & 100
\end{tabular}


Selected Loci Selected Loci

\begin{tabular}{lll}
\hline \% Lipid & 0 & 27 \\
Condition Index & 0 & 5 \\
\hline
\end{tabular}

